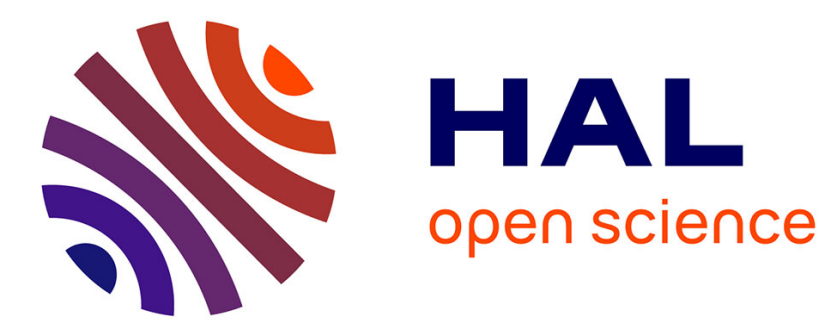

\title{
Stretcher-free high energy nonlinear amplification of femtosecond pulses in rod-type fibers
}

Yoann Zaouter, Dimitris N. Papadopoulos, Marc Hanna, J. Boullet, L. Huang, C. Aguergaray, Frédéric Druon, Eric Mottay, Patrick Georges, Eric Cormier

\section{- To cite this version:}

Yoann Zaouter, Dimitris N. Papadopoulos, Marc Hanna, J. Boullet, L. Huang, et al.. Stretcher-free high energy nonlinear amplification of femtosecond pulses in rod-type fibers. Optics Letters, 2008, 33 (2), pp 107-109. hal-00531815

\section{HAL Id: hal-00531815 https://hal.science/hal-00531815}

Submitted on 30 Mar 2012

HAL is a multi-disciplinary open access archive for the deposit and dissemination of scientific research documents, whether they are published or not. The documents may come from teaching and research institutions in France or abroad, or from public or private research centers.
L'archive ouverte pluridisciplinaire HAL, est destinée au dépôt et à la diffusion de documents scientifiques de niveau recherche, publiés ou non, émanant des établissements d'enseignement et de recherche français ou étrangers, des laboratoires publics ou privés. 


\title{
Stretcher-free high energy nonlinear amplification of femtosecond pulses in rod-type fibers
}

\author{
Y. Zaouter, ${ }^{1,3, *}$ D. N. Papadopoulos, ${ }^{2}$ M. Hanna, ${ }^{2}$ J. Boullet, ${ }^{1}$ L. Huang, ${ }^{1}$ C. Aguergaray, ${ }^{1}$ F. Druon, ${ }^{2}$ \\ E. Mottay, ${ }^{3}$ P. Georges, ${ }^{2}$ and E. Cormier ${ }^{1}$ \\ ${ }^{1}$ Centre Lasers Intenses et Applications, Université de Bordeaux 1, CNRS, CEA 351 cours de la Libération, 33405 \\ Talence, France \\ ${ }^{2}$ Laboratoire Charles Fabry de l'Institut d'Optique, CNRS, Université Paris Sud, 91127 Palaiseau, France \\ ${ }^{3}$ Amplitude Systèmes, 6 allée du Doyen Georges Brus, 33600 Pessac, France \\ *Corresponding author: zaouter@celia.u-bordeaux1.fr
}

Received September 26, 2007; revised November 13, 2007; accepted November 13, 2007; posted November 19, 2007 (Doc. ID 87953); published January 8, 2008

We report on the study of direct amplification of femtosecond pulses in an $80 \mu \mathrm{m}$ core diameter microstructured Yb-doped rod-type fiber amplifier in the nonlinear regime. The system includes a compact single grating compressor for the compensation of the small dispersion in the amplifier. With a $1250 \mathrm{line} / \mathrm{mm}(1 / \mathrm{mm})$ grating-based compressor, pulses as short as $49 \mathrm{fs}$ with $870 \mathrm{~nJ}$ pulse energy and $12 \mathrm{MW}$ peak power are obtained. Alternatively, the use of a $1740 \mathrm{l} / \mathrm{mm}$ grating allows the production of higher quality pulses of $70 \mathrm{fs}, 1.25 \mu \mathrm{J}$ pulse energy, and $16 \mathrm{MW}$ peak power. (C) 2008 Optical Society of America

OCIS codes: $060.2320,140.3510,320.5520$.

A decade of intensive studies and improvements on Yb-doped fibers has led to the demonstration of many advantageous properties if compared to conventional bulk solid-state systems. Thanks to their geometry and design, Yb-doped fibers feature outstanding thermo-optical properties, large gain bandwidth, high saturation fluence, and high optical pumping efficiency $(\sim 80 \%)$. However, the major drawback of ultrashort pulses amplification in doped fibers is the long confined propagation length that limits both the power and the energy scaling due to nonlinear pulse distortions.

In general, sufficient pulse stretching in the time domain together with the enlargement of the mode field area of the active core is used to reduce the peak power and thus limit nonlinear effects. Thus, the socalled fiber chirped-pulse amplification (FCPA) technique implements a stretcher module, a low numerical aperture (NA) large mode area (LMA) rare-earthdoped fiber amplifier, and a compressor module. Recently, this technique has led to the generation of very high power femtosecond pulses [1] as well as hundreds of microjoule-class subpicosecond pulses [2]. Interestingly enough, specific FCPA systems have generated high peak power and high energy pulses in the presence of large amounts of accumulated nonlinear phase [3-5]. In a similar context, parabolic pulse generation and amplification in fiber-based amplifiers clearly denote how nonlinearities can be harnessed, rather than limited, to generate high peak power ultrashort pulses [6,7]. Recently, we have demonstrated the operation of a parabolic amplifier beyond the gain bandwidth limit under conditions of gain-induced spectral asymmetry [8].

In this Letter, we demonstrate the direct amplification of femtosecond pulses in short length, ultralow nonlinearity rod-type photonic crystal fibers [9] to peak powers in excess of $10 \mathrm{MW}$. Our system includes a compressor to compensate the small amount of dispersion accumulated in the amplifier. The amplifier is based on a rod-type photonic crystal fiber with an ultralarge mode field diameter of $70 \mu \mathrm{m}\left(\sim 3850 \mu \mathrm{m}^{2}\right.$ mode field area). In contrast with pure parabolic amplification, the pulses are amplified and spectrally broadened in an unconventional nonlinear regime dominated by self-phase modulation (SPM) in the presence of gain and a limited amount of dispersion (nonlinear length $L_{\mathrm{NL}} \approx 6.8 \mathrm{~cm}$, while dispersion length $L_{D} \approx 4.4 \mathrm{~m}$ ) [10]. We obtained $49 \mathrm{fs}, 870 \mathrm{~nJ}$, $12 \mathrm{MW}$ peak power pulses, and $70 \mathrm{fs}, 1.25 \mu \mathrm{J}, 16 \mathrm{MW}$ peak power pulses, using a 1250 and a 1740 line $/ \mathrm{mm}$ $(1 / \mathrm{mm})$, respectively, grating-based compressor, at a repetition rate of $10 \mathrm{MHz}$ and a central wavelength of $1030 \mathrm{~nm}$. These performances are obtained with a stretcher-free single amplifier stage and are, to our knowledge, the highest peak power ever reported for a system of this type.

Our experimental setup is shown in Fig. 1. The femtosecond seed source is a passively mode-locked $\mathrm{Yb}^{3+}: \mathrm{KYW}$ oscillator and delivers pulses of $330 \mathrm{fs}$ with a spectral bandwidth of $3.9 \mathrm{~nm}$ centered at $1030 \mathrm{~nm}$ [time-bandwidth product (TBP) 0.36 ] with energy of up to $170 \mathrm{~nJ}$ at $10 \mathrm{MHz}$ repetition rate. These pulses (up to $100 \mathrm{~nJ}$ ) are seeded into the rod-type fiber through an optical isolator. The high power amplifier is based on an $85 \mathrm{~cm}$ long low-

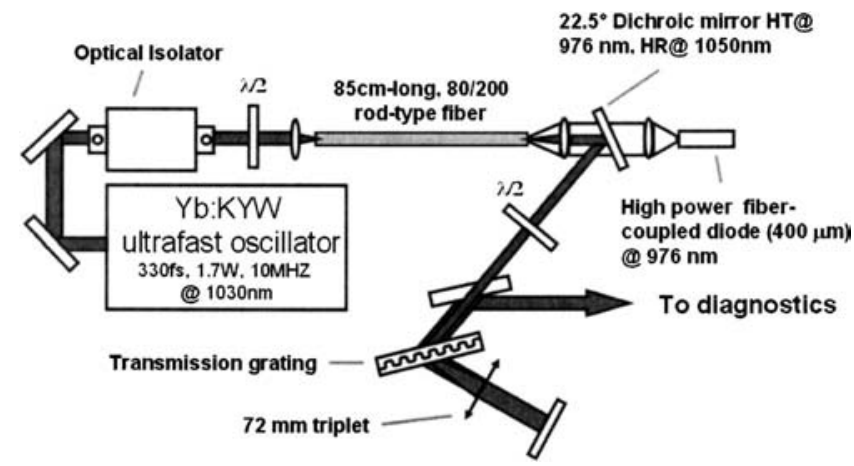

Fig. 1. Experimental setup. 


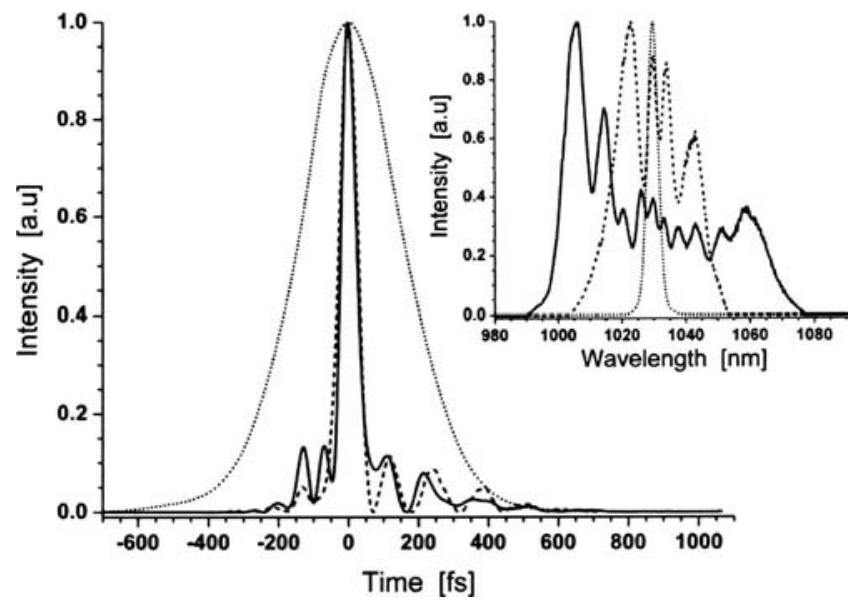

Fig. 2. Retrieved temporal intensity profile (SHG FROG) of the seed (dotted) and compressed pulses at $185 \mathrm{~nJ}$ (dashed) and $870 \mathrm{~nJ}$ (solid) output power (corresponding spectra in the inset) for the $1250 \mathrm{l} / \mathrm{mm}$ grating case.

nonlinearity microstructured Yb-doped rod-type fiber, which delivers diffraction-limited beam quality $\left(M^{2} \sim 1.3\right)$ out of an $80 \mu \mathrm{m}$ core diameter. The fiber is intrinsically monomode due to the microstructure that surrounds the extremely large core and does not require selective injection. Long term (several hours) stability has been achieved, except in the case of high pump power $(>50 \mathrm{~W})$. This is only due to a rather trivial technical restriction, i.e., heating of the pumping optics mounts. The mode field diameter of this fiber of $70 \mu \mathrm{m}$ (corresponding to a nonlinear parameter $\gamma=5.1 \times 10^{-5}$ ) considerably reduces nonlinearities during amplification compared to conventional LMA fibers. The high NA( 0.56) pump cladding has a diameter of $200 \mu \mathrm{m}$ and ensures a pump absorption of $25 \mathrm{~dB} / \mathrm{m}$ at $976 \mathrm{~nm}$. A $100 \mathrm{~W}$ fiber-coupled laser diode emitting at $976 \mathrm{~nm}$ is used to pump the amplifier in a counterpropagating scheme. Both fiber ends are angle polished at $8^{\circ}$ to suppress parasitic lasing.

In fiber amplifier systems the overall uncompensated third-order dispersion (TOD) sets a significant restriction on the generation of high quality sub$100 \mathrm{fs}$ high energy pulses. In previous works $[4,8,11]$ the mechanism of the linear TOD (due to the compressor/stretcher and the fiber material) compensation by SPM induced nonlinear phase shift of spectrally asymmetric pulses has been studied. According to this scheme there is an optimum output pulse power level (i.e., total amount of accumulated nonlinear phase in the fiber) at which TOD compensation is optimized, and therefore the best pulse quality is achieved. In our setup the amplified pulses are recompressed in a two-pass transmission grating-based compressor, which alternatively employs two transmission gratings: a 1250 and a $1740 \mathrm{l} / \mathrm{mm}$, both at Littrow angle of incidence i.e., $40^{\circ}$ and $64^{\circ}$, respectively. As they provide a considerably different TOD to group-velocity dispersion (GVD) ratio of -4 and $-15 \mathrm{fs}$, respectively, we expected to set a different upper limit of the optimum output power level of the amplified pulses. Finally, the recompressed pulses are characterized by means of a second harmonic generation frequency resolved optical gating (SHG FROG) cross-checked with independent intensity autocorrelation (50 ps delay range) and spectrometer measurements, to assure accurate identification of the pulse structure.

We first study the amplification and recompression of the $10 \mathrm{MHz}$ pulse train to an average power of up to $10 \mathrm{~W}$ ( $1 \mu \mathrm{J}$ output energy) with the $1250 \mathrm{l} / \mathrm{mm}$ transmission grating-based compressor. The doublepass geometry allows us to improve the overall compression efficiency to $87 \%$ at maximum output power at the expense of some spatial chirp. However, optimal compression of the $10 \mathrm{~W}$ incident beam is obtained for an equivalent distance between the gratings of only $0.98 \mathrm{~mm}$. In such a case, the entire spectrum is spatially spread over $290 \mu \mathrm{m}$. Compared to a beam diameter of $4 \mathrm{~mm}$ the spatial chirp can be considered insignificant. The SHG FROG retrieved intensity profiles of the seed and amplified pulses at 2 and $10 \mathrm{~W}$ (corresponding to pulse energies after compression of 185 and $870 \mathrm{~nJ}$, respectively) are shown in Fig. 2. At $1.85 \mathrm{~W}$ output average power after compression the pulse duration is already dramatically reduced down to $60 \mathrm{fs}$ due to the SPMinduced spectral broadening (inset of Fig. 2). In Fig. 3 is shown the almost linear decrease of the recompressed pulses duration with the increase of the output power i.e., with the increase of the spectral bandwidth/nonlinear phase. At the highest output power of $8.7 \mathrm{~W}$ after compression the pulse duration is shortened down to $49 \mathrm{fs}$, with FWHM timebandwidth product (TBP) of 0.47 and rms TBP of 3.7. However, the amount of energy contained into the main pulse peak decreases from $77 \%$ at $1.85 \mathrm{~W}$ down to $65 \%$ at $8.7 \mathrm{~W}$, due to uncompensated TOD, corresponding to an actual peak power of 2.4 and 12.1 MW, respectively. A further increase of the output power resulted in severe distortion of the pulse structure, making its characterization uncertain.

To optimize the compensation of both the GVD and the TOD we replaced the $1250 \mathrm{l} / \mathrm{mm}$ grating with a 1740 l/mm grating, for which the TOD to GVD ratio is 3.7 times larger. In Fig. 4 is shown the retrieved

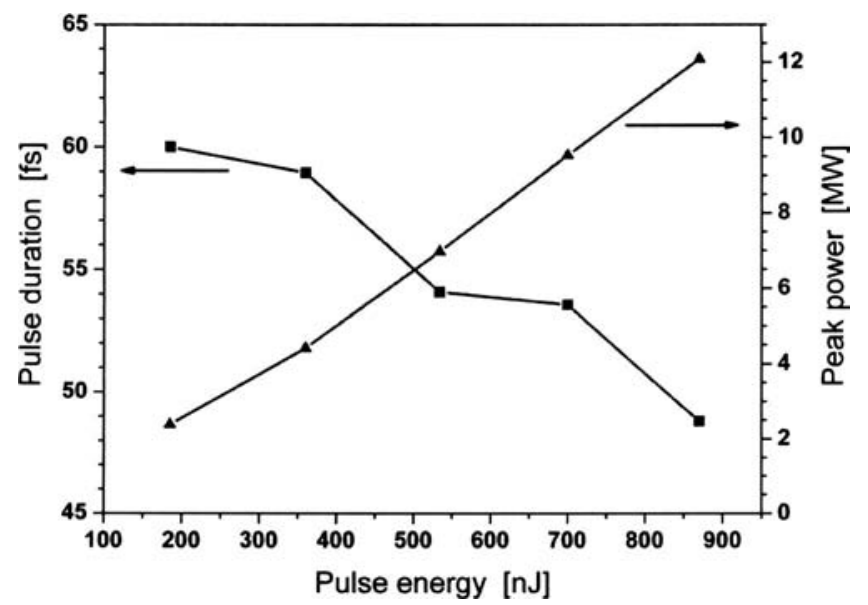

Fig. 3. Pulse duration and corresponding peak power as a function of output energy for the $1250 \mathrm{l} / \mathrm{mm}$ transmission grating. 


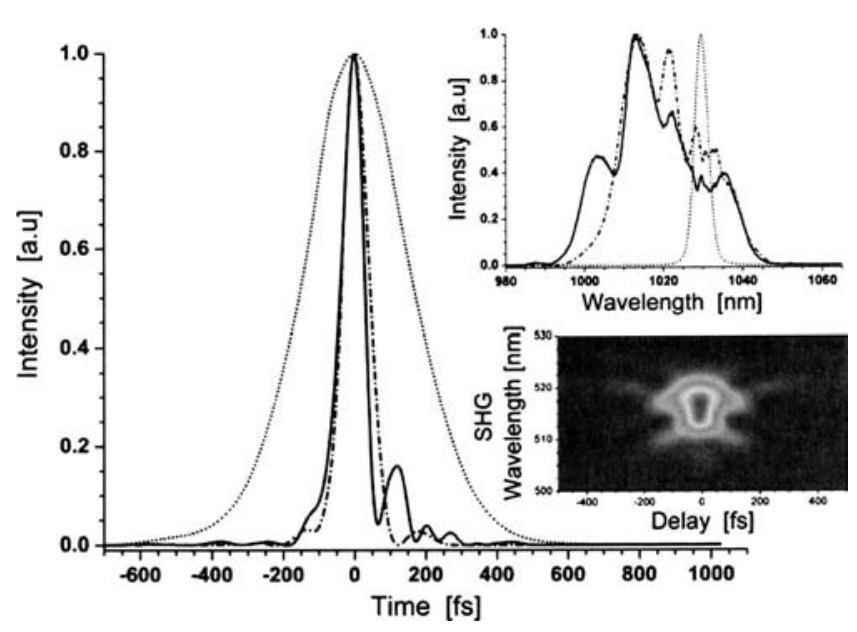

Fig. 4. Retrieved temporal intensity profile for the seed (dotted) and best quality recompressed pulse (dash dot), and the highest peak power pulse (solid) with corresponding spectra (top inset). SHG FROG for the highest peak power case (bottom inset).

intensity profiles in the cases of the best quality recompressed pulses, and the highest peak power pulses. For $8.5 \mathrm{~W}$ of amplified power $(5.6 \mathrm{~W}$ after compression) the quality of the compressed pulses is excellent, resulting in more than $95 \%$ of the total energy contained in the $84 \mathrm{fs}$ duration main pulse peak. The shortest recompressed pulses are obtained for $16 \mathrm{~W}$ of amplified power (10 W or $1 \mu \mathrm{J}$ after compression), where the pulse duration decreases down to $64 \mathrm{fs}$. The highest peak power is obtained at $\sim 80 \mathrm{~W}$ of pump power resulting in $20 \mathrm{~W}$ output power (12.5 W or $1.25 \mu \mathrm{J}$ after compression, estimated B integral is $8.7 \pi$ ), where $89 \%$ of the total energy is concentrated in the $70 \mathrm{fs}$ main pulse peak (FWHM TBP of $0.58, \mathrm{rms}$ TBP of 2.4), corresponding to $16 \mathrm{MW}$ peak power. The evolution of the recompressed pulse duration and peak power versus output energy is shown in Fig. 5. It can be seen that the pulse duration decreases with increasing output energy as was already observed in the $1250 \mathrm{l} / \mathrm{mm}$ grating-based compressor case but levels off for the highest ener-

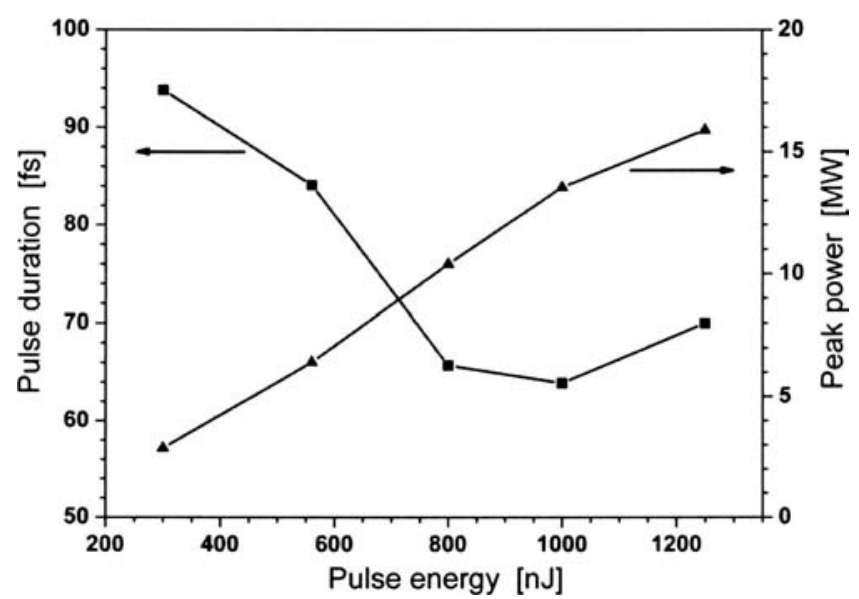

Fig. 5. Pulse duration and corresponding peak power as a function of output energy for the $1740 \mathrm{l} / \mathrm{mm}$ transmission grating. gies. This behavior is attributed both to the nonoptimized TOD compensation but most significantly to the strong spectral filtering of the highly dispersive grating for wavelengths higher than $1045 \mathrm{~nm}(\sim 17 \%$ of the total energy), resulting in an $\sim 62 \%$ compression efficiency at the highest peak power. The use of improved bandwidth $1740 \mathrm{l} / \mathrm{mm}$ gratings could lead to sub-40 fs pulse with energy of $\sim 2 \mu \mathrm{J}$ and, therefore, peak power in excess of $40 \mathrm{MW}$.

In conclusion, we have demonstrated the production of $16 \mathrm{MW}$ peak power pulses at $10 \mathrm{MHz}$ repetition rate from a stretcher-free $\mathrm{Yb}$-doped rod-type fiber amplifier operating in the nonlinear regime. This approach is based on direct amplification of narrowband pulses in a single-pass Yb-doped rod-type fiber involving embedded gain and SPM. A compact transmission grating compressor is used to compensate for the small dispersion accumulated in the amplifier. We show that the use of rod-type fibers results in peak power four times larger than the highest reported [8] obtained with conventional LMA fibers. Optimized gratings should allow reaching the $40 \mathrm{MW}$ level in the same configuration. Such a laser source could be used for high field physics experiments such as direct generation of high harmonics and attosecond pulses at a high repetition rate.

The authors acknowledge the financial support of the Conseil Régional d'Aquitaine, the Laserlab consortium, the Agence National de la Recherche under research program HIPOLYFF, and the Réseau des Technologies Femtoseconde. D. N. Papadopoulos acknowledges the financial support of the Région Ile de France for his postdoctoral position.

\section{References}

1. F. Röser, J. Rothhard, B. Ortac, A. Liem, O. Schmidt, T. Schreiber, J. Limpert, and A. Tünnermann, Opt. Lett. 30, 2754 (2005).

2. F. Röser, D. Schimpf, O. Schmidt, B. Ortaç, K. Rademaker, J. Limpert, and A. Tünnermann, Opt. Lett. 32, 2230 (2007).

3. L. Shah, Z. Liu, I. Hartl, G. Imeshev, G. Cho, and M. Fermann, Opt. Express 13, 4717 (2005).

4. L. Kuznetsova and F. W. Wise, Opt. Lett. 32, 2671 (2007).

5. A. Chong, L. Kuznetsova, and F. W. Wise, J. Opt. Soc. Am. B 24, 1815 (2007).

6. M. E. Fermann, V. I. Kruglov, B. C. Thomsen, J. M. Dudley, and J. D. Harvey, Phys. Rev. Lett. 84, 6010 (2000).

7. J. Limpert, T. Schreiber, T. Clausnitzer, K. Zöllner, H.-J. Fuchs, E.-B. Kley, H. Zellner, and A. Tünnermann, Opt. Express 10, 628 (2002).

8. D. N. Papadopoulos, Y. Zaouter, M. Hanna, F. Druon, E. Mottay, E. Cormier, and P. Georges, Opt. Lett. 32, 2520 (2007).

9. J. Limpert, O. Schimdt, J. Rothhardt, F. Röser, T. Schreiber, A. Tünnermann, S. Ermeneux, P. Yvernault, and F. Salin, Opt. Express 14, 2715 (2006).

10. C. Finot, F. Parmigiani, P. Petropoulos, and D. Richardson, Opt. Express 14, 3161 (2006).

11. S. Zhou, L. Kuznetsova, A. Chong, and F. Wise, Opt. Express 13, 4869 (2005). 